\title{
THE REGULATION OF SYNAPTIC STRENGTH WITHIN MOTOR UNITS OF THE FROG CUTANEOUS PECTORIS MUSCLE ${ }^{1}$
}

\author{
LAURENCE O. TRUSSELL AND ALAN D. GRINNELL \\ Departments of Biology and Physiology, Jerry Lewis Neuromuscular Research Center, Ahmanson Laboratory for Neurobiology, \\ University of California, Los Angeles, California 90024
}

Received April 2, 1984; Revised June 1, 1984; Accepted June 6, 1984

\begin{abstract}
The physiological properties of frog neuromuscular junctions may vary widely in a single muscle. In order to understand the factors that contribute to this variation, we have studied populations of synapses belonging to individual motor units of the frog cutaneous pectoris muscle. Motor units in this muscle differ widely in twitch strength. A motor axon's synaptic contacts could be found throughout the muscle, at both singly and polyneuronally innervated endplates. Indeed, over $36 \%$ of the endplates contacted by each isolated motor axon were polyneuronally innervated. Comparisons of synapses on muscle fibers in large twitch motor units with those in small twitch motor units reveal that endplate potential amplitude, transmitter release, and muscle fiber diameter are positively correlated with the strength of the motor unit contraction. Large and small twitch motor units differ more in their transmitter release than in their nerve terminal length, indicating that larger twitch motor units have a higher relcase per unit length of terminal. Among motor units of roughly similar twitch tension, transmitter release at endplates receiving only one axonal input is remarkably constant, independent of postsynaptic muscle fiber input resistance, or, presumably, nerve terminal size. In cases where two different motor axons contribute to a single endplate, the synaptic strength of each input is again related to properties of the contributing motoneuron, although the individual synaptic inputs are markedly reduced in strength and size relative to singly innervated endplates. Additionally, the diameter of polyneuronally innervated muscle fibers appears related to properties of both innervating motoneurons. Thus, the pre- and postsynaptic characteristics of neuromuscular junctions may be determined both by the motoneuron and by peripheral interactions between motoneurons.
\end{abstract}

Recent work has shown that neuromuscular junctions are dynamic structures, physiologically and morphologically malleable in response to a variety of influences, including hormonal states, use, age, change in target tissue mass, and axotomy of contralateral homologous motoneurons (Grinnell and Herrera, 1981; Rotshenker, 1982; Kelly and Robbins, 1983). 'These regulatory influences are superimposed on basic synaptic properties that appear to be determined principally by two factors. Perhaps most important is the "intrinsic" capability of each motoneuron to maintain synapses and release transmitter (Davis, 1971; Ridge and Thomson, 1980b; Grinnell and Trussell, 1983). In addition, the strength of an individual synaptic contact appears to be strongly influenced by the presence of neighboring inputs to the same fiber (Angaut-Petit and Mallart, 1979; Grinnell et al., 1979; Nudell and Grinnell, 1983; Weakly and Yao, 1983). In the frog sartorius, motor units may differ markedly in the mean strength of their synapses, suggesting intrinsic differences between motoneurons innervating the

${ }^{1}$ We would like to thank B. Nudell, P. Sargent, and M. Schwartz for helpful discussions. F. Knight provided excellent technical assistance. This research was supported by United States Public Health Service Grant NS06232, and by a grant from the Muscular Dystrophy Association. L. O. T. was supported by a University of California graduate fellowship and by a grant from the Muscular Dystrophy Association. muscle (Grinnell and Trussell, 1983). However, since virtually all sartorius muscle fibers have multiple endplates, and are likely to receive contact from more than one axon, it is difficult to distinguish the relative importance of synaptic competition and inherent differences in motoneuron capabilities. A preparation in which these influences may be more clearly resolved is the frog cutaneous pectoris muscle (c.p.), in which fibers have only one endplate, which may be singly or polyneuronally innervated (Letinsky et al., 1976).

In this report, we describe an analysis of the properties of synapses within identified motor units of the frog c.p. muscle. These results show that differences in mean endplate potential (EPP) size and transmitter release among motor units of different twitch tension are manifest even among singly innervated muscle fibers. Thus, the strength of a synapse reflects an intrinsic property of the motoneuron. This intrinsic property is also reflected in the strength of inputs to polyneuronally innervated endplates, with "weaker" motoneurons making a relatively minor contribution to the total EPP, while "stronger" motoneurons are frequently dominant. Finally, the identity of the motoneuron and the presence of polyneuronal innervation appear to have marked effects on muscle fiber size. A preliminary report of some of these results has already appeared (Trussell, 1983).

\section{Materials and Methods}

Rana pipiens were obtained from Wisconsin ("Northern" frogs, body length of 6.5 to $7.9 \mathrm{~cm}$, supplied by Nasco) or from Tennessee ("South- 
ern" frogs, body length of 7.7 to $9.1 \mathrm{~cm}$, supplied by Carolina Biologicals). The c.p. muscles were dissected free along with their associated spinal root and pinned out to $110 \%$ of their in situ length in a Sylgard (Dow Corning) lined bath. Normal frog Ringer (116 mM NaCl, $2 \mathrm{mM}$ $\mathrm{KCl}, 1.8 \mathrm{~mm} \mathrm{CaCl}_{2}$, and $5 \mathrm{~mm}$ HEPES, buffered to $\mathrm{pH} 7.2$ ) was continuously superfused. Bath temperature was kept at $12 \pm 1^{\circ} \mathrm{C}$. For tension measurement, a Statham UC-3 or a more sensitive transducer built in the laboratory was attached to the muscle via a $1-\mathrm{cm}$ minuten pin threaded through the flap of skin removed with the muscle. Although the attached skin must introduce some isotonic component to the contraction, the pin was generally no more than $1 \mathrm{~mm}$ from the narrow c.p. tendon and the method ensured an even transfer of tension from all points in the muscle to the transducer.

Extracellular recordings of c.p. nerve action potentials were made by looping the nerve around a platinum hook electrode at a point just before the nerve's entry into the muscle, so that all axons recorded were likely to be c.p. axons. The recording site was insulated from the bath with vaseline-mineral oil or Glyseal (Boher Chemie) and the recordings were made relative to ground. This electrode also was used to stimulate the whole nerve by passing through it suprathreshold, electrically isolated $0.05-\mathrm{msec}$ pulses at $0.33 \mathrm{~Hz}$. During intracellular recordings, a light transmission block was maintained with $6.0 \mu \mathrm{M}$ $d$-tubocurarine chloride (ICN) in the Ringer, except when examining miniature EPPs, which were recorded in normal Ringer. Intracellular recordings were made with 30 to $60 \mathrm{M} \Omega$ microelectrodes filled with 0.6 $\mathrm{M} \mathrm{K}_{2} \mathrm{SO}_{4}$ (saturated) and $0.1 \mathrm{M} \mathrm{KCl}$.

For experiments in which only twitch and tetanic tensions were measured, motor units were isolated by the dissection of single axons from the c.p. nerve, as described by Grinnell \& Trussell (1983). Twitch and tetanic tensions were evoked by 0.05 -msec pulses at 0.33 and 50 $\mathrm{Hz}$, respectively. For electrophysiological experiments, the second spinal root, cut close to the spinal cord, was drawn up into a snugly fitting suction electrode. Just distal to the point of stimulation, the nerve was progressively sectioned with an iridectomy scissors until one to three c.p. motor axons remained intact. The number of intact motor axons was monitored both by the number of tension increments seen with increasing stimulus voltage (also with 0.05 -msec pulses at 0.33 $\mathrm{Hz}$ ) and by the corresponding changes in the appearance of the extracellular action potential profile recorded close to the muscle. In this way, one could determine which change in action potential profile corresponded to a given change in tension. After curare block, the nerve action potentials were used as a monitor for the identity of the motor unit giving rise to a particular EPP. The action potential profile was generally free of stimulus-evoked sensory axon spikes (small size potentials not corresponding to muscle twitches) if the nerve dissection was performed in the main spinal nerve trunk. Experiments were only continued if the changes in the size and shape of the action potential observed when a motor unit was recruited were unambiguous and consistent. Because of this criterion, only rarely could more than two (and never more than three) motor units be studied in one muscle. The advantage of this method of motor unit isolation, compared to singleaxon or ventral rootlet dissection, was that motor units remained viable for at least $6 \mathrm{hr}$, and better tolerated physical manipulations. Although smaller motor unit twitches appeared correlated with smaller, slower conducting axonal action potentials (Luff and Proske, 1976), the short length of nerve from spinal cord to c.p. (about $1.5 \mathrm{~cm}$ ) did not permit accurate resolution of these parameters.

While in initial experiments, a motor unit's muscle fibers were located by the detection of extracellular synaptic currents; it was found to be just as convenient, and more informative, to start at one edge of the muscle (lateral or medial) and move across it, penetrating every surface fiber while looking for EPPs evoked by stimulation of the isolated motor units. Usually, from five to 12 muscle fibers belonging to a single motor unit could be found with this method. Fibers were rejected if resting potentials were less than $-80 \mathrm{mV}$. Endplates were located by the brief rise time of the EPP ( 1.5 to $2.0 \mathrm{msec}$ ). Furthermore, as the preparation was viewed with a $\times 20$ water-immersion objective ( $\times 200$ total), preterminal myelinated branches and Schwann cell bodies were easily resolved, and frequently synaptic gutters could be recognized. When a fiber belonging to one of the isolated units was found, 5 to 10 EPPs were recorded on film. The presence of polyneuronal innervation was determined by comparing the size of the identified motor unit's EPPs to the size of the EPPs evoked upon wholenerve stimulation through the hook electrode. A second microelectrode was then inserted within $100 \mu \mathrm{m}$ from the first microelectrode and several 300-msec hyperpolarizing pulses passed to measure the input resistance of the fiber.

Significant depression of EPPs was observed if stimulation was prolonged for more than a few minutes, possibly as a result of a presynaptic action of curare (Otsuka et al., 1962; Magleby et al., 1981). Because of this, usually only 5 EPPs were averaged for each cell, and several minutes elapsed between recording from successive cells. EPPs were normalized to $-90 \mathrm{mV}$ without correction for nonlinear summation as most responses were less than $15 \%$ of the resting potential (McLachlan and Martin, 1981). To check for overall decline of the preparation at the end of the experiment, cells that had been studied early in the experiment were repenetrated and EPPs were measured. Generally, EPPs were within $15 \%$ of their original values, and so no corrections for depression were made.

Due to irregularities in muscle fiber shape and the overlap of neighboring fibers, estimation of fiber diameter from electrical properties are likely to be more precise than simple in situ measurements with the light microscope. Muscle fiber size was calculated from input resistance by the relation.

$$
D=\left(\frac{\frac{1}{\pi} \sqrt{R_{\mathrm{m}} R_{\mathrm{i}}}}{R_{\mathrm{o}}}\right)^{2 / 3}
$$

where $D$ is diameter, $R_{\mathrm{o}}$ is input resistance, $R_{\mathrm{m}}$ is the specific resistivity of the muscle membrane, taken to be $4000 \Omega-\mathrm{cm}^{2}$, and $R_{\mathrm{i}}$ is the specific resistivity of myoplasm, taken to be $250 \Omega-\mathrm{cm}$ (Katz, 1948). Two control experiments were performed in which input resistances were measured, the muscle was fixed in $2 \%$ glutaraldehyde, and the studied fibers were dissected out and their diameters were measured under $\times 400$ magnification (Fig. 1). Measured and calculated diameters were in very good agreement $(r=0.91$, slope $=0.91)$. Deviations from a slope of unity probably derive, in part, from the elliptical or triangular appcarance of fibers in cross-section, which would generate errors both in the measured diameter and in the calculated diameter, since the above equation assumes a long cylinder which is circular in cross-section (Katz, 1948).

Direct measurement of quantal content was not useful in these experiments because of the need to retain the detectability of polyneuronal innervation. Transmitter release was therefore estimated by normalizing EPP amplitudes for muscle fiber input resistance (EPP $\times$ (1 $\mathrm{M} \Omega$ /input resistance of fiber)). The interpretation of curarized

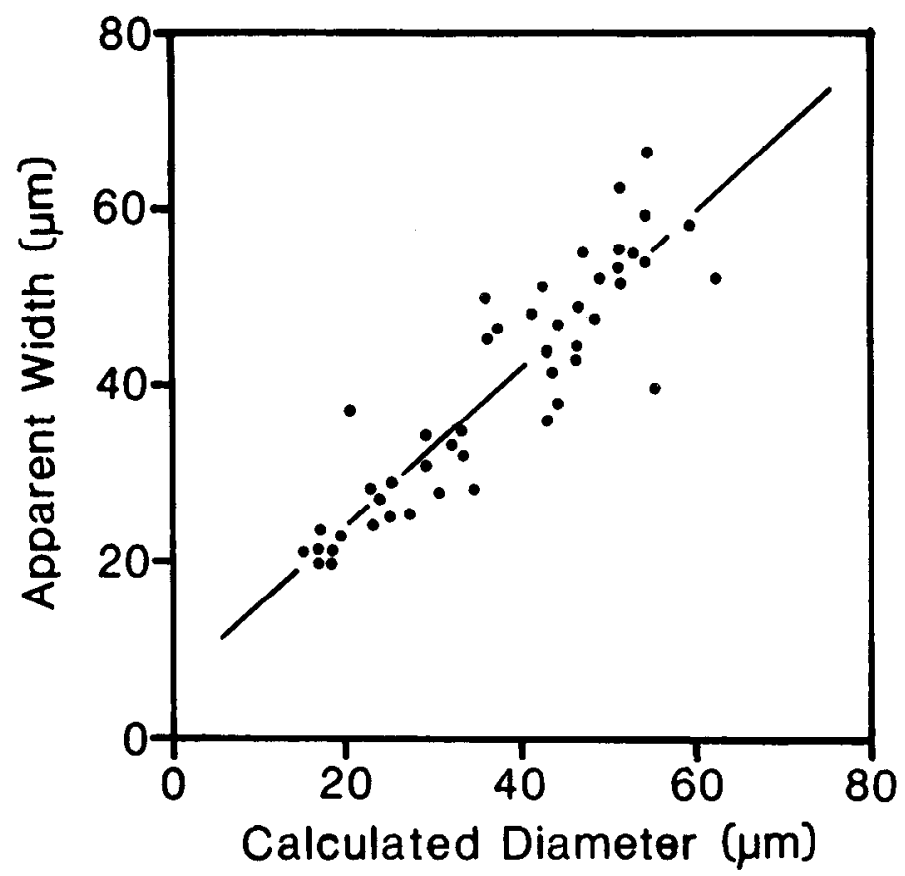

Figure 1. Comparison of muscle fiber diameters measured by eye (ordinate) to those calculated from input resistance as in text (abscissa). After measurement of input resistance, the preparation was fixed in $2 \%$ glutaraldehyde-Ringer; the fibers that had been recorded from were dissected out and their diameters were measured at several points along their length with $\times 400$ optics. $n=48$, correlation coefficient $=0.91$. 
endplate potentials in terms of the amount of transmitter released requires that the size of the single quantum response should follow closely the postsynaptic input resistance. Comparisons of miniature EPP (MEPP) size and muscle fiber input resistance have shown that the average current that results from one transmitter quantum is surprisingly constant in frog muscle (Katz and Thesleff, 1957; Nudell and Grinnell, 1982). This has been confirmed in the present work for the frog c.p. muscle. Input resistance and average MEPP size were measured for 59 cells from five muscles; the correlation coefficient for input resistance vs. MEPP amplitude was 0.92 (graph not shown). This relationship suggests that, for muscle fibers of identical input resistance, differences in EPP size should directly reflect corresponding differences in quantal release (as long as nonlinear summation can be neglected; see above). For fibers of different input resistance and identical EPP sizes, the smaller fibers are receiving less transmitter, in proportion to their higher single quantum response. Indeed, direct comparisons between EPPs normalized for input resistance and actual quantal contents are in good agreement (Nudell and Grinnell, 1982).

The lengths of nerve terminals from physiologically identified muscle fibers were measured as in Grinnell and Herrera (1980) using the combined nitroblue tetrazolium-Karnovsky method (Letinsky and DeCino, 1980). Terminal length was taken to be the total length of presynaptic element lying immediately over a cholinesterase-stained gutter. In some cases of polyneuronal innervation, it was clear that two nerve terminals occupied the same gutter. It is possible that adjacent terminals lying in the same gutter occasionally were not resolved as separate, leading to an underestimation of the total terminal length. However, this situation is most common with regenerated synapses (Rotshenker and McMahan, 1976); the normal incidence of shared gutter appears to be less than 3\% (Morrison-Graham, 1983; A. Herrera, personal communication; A. Wernig, personal communication) and so is not likely to contribute serious error to the measurement of the total length of polyinnervated synnapses.

Comparisons of sample means and the significance of correlations were tested with Student's $t$ test. Unless otherwise stated, statistical significance was assumed for $p<0.01$.

\section{Results}

\section{Motor unit twitch and tetanic tension}

Tetanus and twitch tensions were recorded from 100 motor units (14 muscles) to establish the range of apparent motor unit sizes and to examine the relationship between tetanus and twitch tension for motor units of different size. These data are presented in histogram form in Figure 2, where tensions are expressed as a percentage of the whole nerve-evoked tension of each muscle. Tetanus and twitch tension vary over $13-$ and $62-$ fold ranges, respectively, and do not appear to form discrete populations. Of particular note is the rarity of very small motor units, which are comparatively abundant in the frog sartorius muscle and are associated with a high frequency of subthreshold synaptic inputs (Grinnell and Herrera, 1980; Grinnell and Trussell, 1983). For example, only 1\% of the c.p. motor units, but over $16 \%$ of sartorius motor units, each produced less than $1 \%$ of the whole nerve-evoked twitch tension (Grinnell and Trussell, 1983).

In the frog sartorius, the ratio of tetanus to twitch tension has been shown to be an indicator of motor unit mean synaptic strength (motor units of lower synaptic strength have many fibers whose EPPs only reach threshold during the tetanus). $\Lambda \mathrm{s}$ in the sartorius, small twitch motor units of the c.p. tend to have higher tetanus-twitch ratios and therefore a lower mean synaptic strength: motor units whose twitch was less than $6 \%$ of the whole muscle twitch had a mean tetanus-twitch ratio of $9.3 \pm 9.6( \pm \mathrm{SD} ; n=23)$, while motor units larger than $14 \%$ had a mean ratio of $3.7 \pm 1.3(n=38)$. As will be seen below, direct measurements of EPP size confirm these estimations based on tension.

\section{Motor unit topography}

The c.p. muscle consists of about 550 muscle fibers distributed in a broad sheet, approximately four fibers thick (Rot-

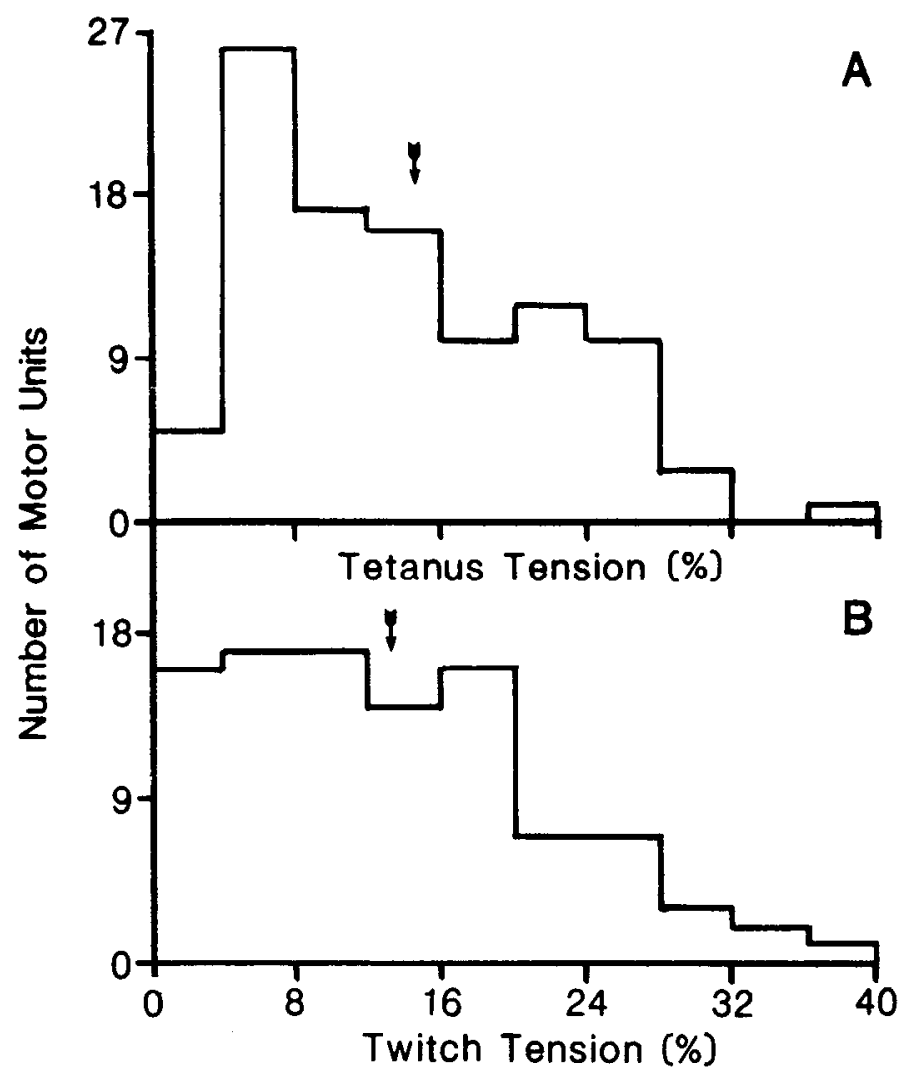

Figure 2. Histograms of tetanus and twitch tension from frog c.p. motor units, expressed as percentages of the whole nerve-evoked tetanus and twitch tension in each experiment. Included are 100 motor units from 14 muscles. Means (arrows) are $14.0 \pm 7.9 \%( \pm \mathrm{SD})$ and $12.9 \pm 8.5 \%$ for tetanus and twitch tensions, respectively.

shenker and McMahan, 1976). Muscle fibers belonging to individual motor units, as identified by intracellular recording, appeared singly or in small clusters of up to four to five fibers. While most of a motor unit's muscle fibers were restricted to about half the muscle's breadth, generally some fibers could be observed throughout the full extent of the muscle. Single axons, even from the smaller twitch motor units, appeared to be highly branched, since the synapses belonging to a single motor unit were found to derive from many different nerve twigs in the muscle. On three occasions, after locating a motor unit's fihers on the muscle's dorsal surface, the muscle was turned over and recordings were made on the ventral surface: synapses from a motor unit could be found on both faces of the muscle, further indicating the wide ramifications of individual c.p. motor axons. The wide dispersal of a motor axon's target cells has also been observed in muscle of the cat and rat (Krnjevic and Miledi, 1958; Kugelberg et al., 1970; Burke and Tsairis, 1973; Burke, 1981) and may be a consequence of the extensive ramifications axons make in developing muscle prior to the initial formation of synapses (Linden and Letinsky, 1983). However, more consolidated innervation does occur in some preparations, perhaps according to the kinesiological requirements of the muscle (Dennis et al., 1981; B. Nudell, unpublished observations).

\section{Electrophysiological studies of motor unit synapses}

The relationship between tetanus-twitch ratio and twitch size discussed above implies a positive relationship between motor unit twitch tension and average EPP size. The latter two parameters are compared in Figure 3, which shows a correlation coefficient of only mild significance $(r=0.50)$. Indeed, while the synapses of larger twitch motor units do tend to generate 


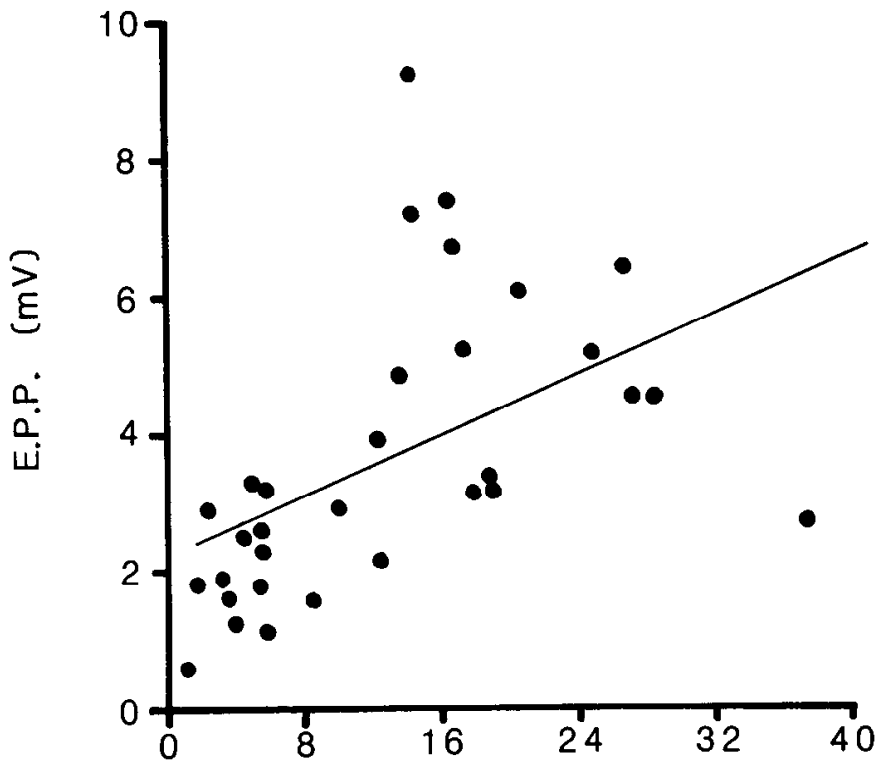

\section{\% TWITCH TENSION}

Figure 3. The average EPP size recorded in each motor units $v s$. the motor unit relative twitch tension (percentage of the whole muscle twitch). Included are EPPs from both singly and polyinnervated endplates. $n=32$ (15 muscles). Correlation coefficient $=0.50(p<0.01)$.

larger EPPs, a marked variability in synaptic properties is apparent among motor units of similar twitch size and even within single motor units. This variability will be discussed in later sections. A clearer impression of the properties related to motor unit size can be obtained by comparing motor units at opposite ends of the size spectrum. For much of what follows, therefore, data were grouped into two classes: $(a)$ motor units whose twitch tension was less than $9 \%$ ("small twitch" motor units); and $(b)$ those greater than $14 \%$ of the whole muscle twitch ("large twitch" motor units). These values were chosen because each group included at least $39 \%$ of the total data pool and relatively little correlation was observed between synaptic strength and motor unit size with either population. In addition to this grouping, cells were further subdivided according to whether or not their endplates were singly or polyneuronally innervated (henceforth "polyinnervated").

\section{Properties of singly innervated synapses}

Values for mean EPP, transmitter release, input resistance, and fiber diameter for large twitch and small twitch motor units are given in Table I. The singly innervated fibers of the small twitch motor units were characterized by having a mean EPP less than half as large as singly innervated fibers of large twitch motor units. Due to differences in muscle fiber size (see below), the mean values of EPP amplitude reflect much larger differences in transmitter output: nerve terminals of large twitch motor units release six times as much transmitler as terminals of small twitch motor units. That those highly significant differences exist when singly innervated junctions alone are considered suggests that they are characteristics intrinsic to the motor unit and are not maintained by ongoing competitive interactions at the single fiber level.

The singly innervated muscle fibers of small and large twitch motor units also differ greatly in their diameter. In Figure 4 (solid lines), frequency histograms of muscle fiber diameter show that singly innervated fibers in small twitch motor units average about half the mean diameter of fibers in large twitch motor units (see also Table I). The extensive overlap in the ranges of fiber diameter between large and small motor units may be an artifact of pooling data from many animals of different size: among nine experiments in which both a large and small twitch motor unit had been isolated, six showed no overlap in the range of large and small motor unit fiber diameters, while in three the overlap was less than $10 \%$ (see "Variability within Single Motor Units").

It is well established that synapse size, transmitter release, and muscle fiber size are closely linked (Harris, 1954; Coërs, 1955; Coërs and Woolf, 1959; Anzenbacher and Zenker, 1963; Granbacher, 1971; Kuno et al., 1971; Korneliussen and Waerhaug, 1973; Bennett and Pettigrew, 1975; Harris and Ribchester, 1979; Grinnell and Herrera, 1980). It is therefore of interest to determine to what extent the 6-fold differences in mean transmitter release between large and small twitch motor units can be explained by differences in nerve terminal length. While nerve terminal lengths were not measured for identified motor units in these experiments, this question may still be approached by examining the normal correspondence of terminal length and fiber diameter found among randomly selected c.p. fibers. In Figure 5, nerve terminal length is plotted against muscle fiber diameter (measured from input resistance) for 103 cells from six experiments. The fit of a linear regression to these points is significant $(r=0.82)$. Using this regression line to approximate the terminal lengths of muscle fibers of known width, the mean terminal length for large twitch motor units (53- $\mu \mathrm{m}$ mean fiber diameter; see Table I) should be around 930 $\mu \mathrm{m}$, while that for small twitch motor units $(27-\mu \mathrm{m}$ mean fiber diameter) should be close to $423 \mu \mathrm{m}$. This indicates that differences between large and small motor units in transmitter release are greater than can be explained by synapse size, and

TABLE I

Mean values $( \pm S D)$ for nine classifications of data from electrophysiological studies of cp motor units, twitch sizes grouped as in text SI, singly innervated junctions; PI, polyinnervated junctions.

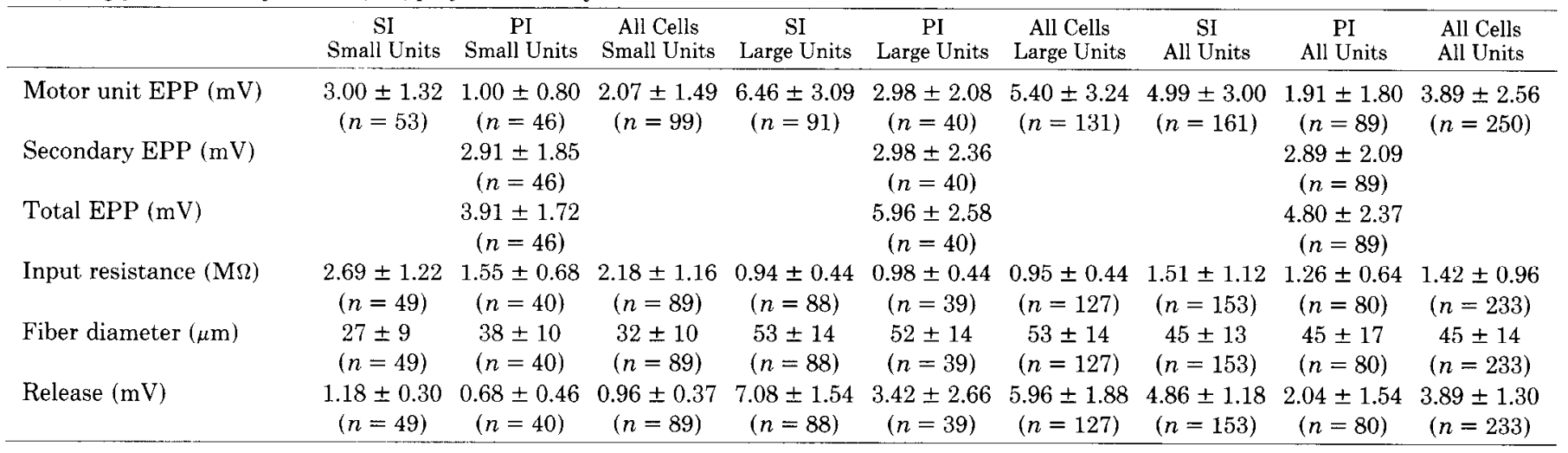



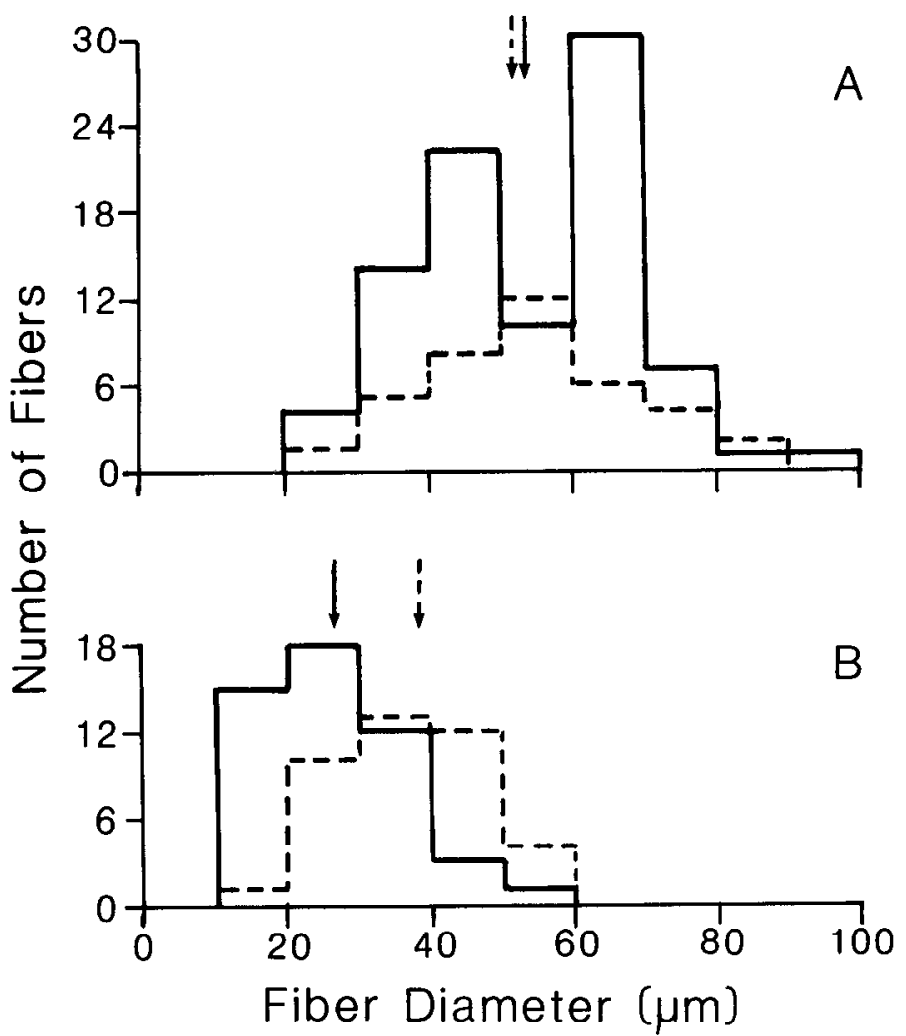

Figure 4. Frequency histograms of muscle fiber diameter for identified large $(A)$ and small $(B)$ twitch motor units. Solid and dashed lines are distributions for singly and polyinnervated muscle fibers, respectively. Means (arrows) for large motor unit singly and polyinnervated fibers are $53 \pm 14$ and $52 \pm 14 \mu \mathrm{m}( \pm$ SD) and those for small unit singly and polyinnervated fibers are $27 \pm 9$ and $38 \pm 10 \mu \mathrm{m}$, respectively. Means for large and small motor unit singly innervated fibers, as well as for small motor unit singly and polyinnervated fibers are significantly different $(p<0.01)$.

must reflect differences in the ability of these motoneurons to release transmitter, manifested in the probability of release per unit length of nerve terminal.

This observation has important consequences for the interpretation of the relationship between fiber size and transmitter release. It is likely that during development, the growth of muscle fibers is accompanied by increases in transmitter release (Letinsky, 1974; Kelly and Robbins, 1983; Morrison-Graham, 1983; Lnenicke and Mellon, 1983). However, correlations between transmitter release and fiber size made from a population of fibers taken from animals of similar age (Kuno et al., 1971) may be more a reflection of diversity in the properties of different motor units than an indication of a developmental progression. In Figure 6A, transmitter release is plotted against fiber diameter for singly innervated fibers of large (circles) and small (triangles) twitch motor units. By considering motor unit identity, it is clear that larger fibers are given more transmitter as a consequence of the type of motor axon innervating them. Indeed, within either motor unit size class, little if any correlation is observed between transmitter release and fiber size, nor is any tendency for positive or negative correlation observed for individual motor units. Furthermore, this uniformity of release appears to be maintained even over a significant range of animal size: included in these samples are data from Northern $R$. pipiens (filled symbols) and the larger Southern $R$. pipiens (open symbols). While the synapses of larger frogs did tend to contact larger muscle fibers, they did not show any tendency to release more transmitter, for either motor unit size class. These data are consistent with the hypothesis that, for adult

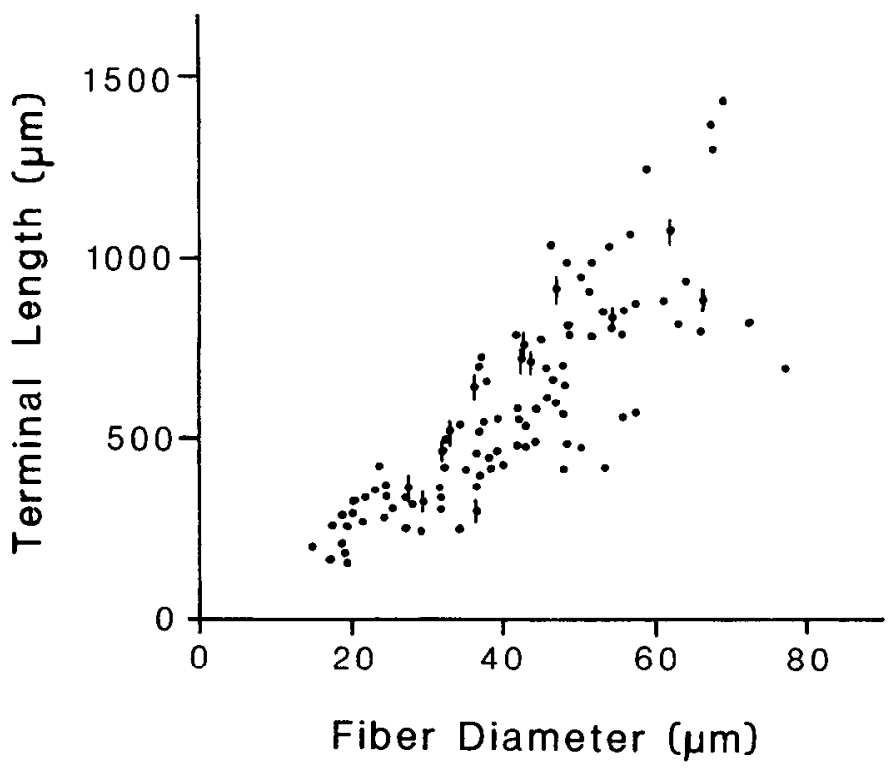

Figure 5. Nerve terminal lengths for 103 c.p. fibers plotted against their corresponding muscle fiber diameter. Muscle fiber diameter was calculated from input resistance as in text. The linear correlation coefficient is 0.82 . Points with vertical lines indicate endplates which had been determined physiologically to be polyinnervated. As the presence of multiple inputs was not tested for every fiber shown in this figure, the fraction of the total data pool that shows polyinnervation should not be taken as indicative of the actual percentage in the muscle.

animals, the transmitter release of singly innervated endplates appears to be largely determined by the motoneuron, independent of postsynaptic differences. During development, when more pronounced growth occurs, it is likely that all motor units increase their fiber size and transmitter output together.

If transmitter release is roughly constant throughout a range of muscle fiber sizes for motor units of similar twitch size, then one might expect that the EPP (not normalized for input resistance), and thus the safety factor of transmission, should decline with increasing fiber size. A significant tendency for this decline in EPP amplitude is illustrated in Figure 7, where the mean EPP values for each of 15 large twitch and 14 small twitch motor units are plotted against the corresponding mean muscle fiber input resistances. Within a twitch size class, motor units of lower input resistance (larger fibers) had a lower mean EPP. Among the fibers of individual motor units, this tendency was not as clear cut: only in $34 \%$ (11 of 32) of the experiments was there a significant positive correlation between the EPP amplitude and input resistance of individual cells, with the remaining experiments showing no correlation.

\section{Properties of polyinnervated synapses}

Polyinnervated endplates provide an opportunity to study how interactions between axon terminals affect transmitter release and postsynaptic properties and how the properties of the innervating motoneurons may determine the outcome of such interactions. The presence of polyinnervation was tested by comparing the amplitude of the EPP evoked by single axon stimulation to that evoked by whole nerve stimulation. Control studies in which polyinnervation was detected by graded stimulation to the whole nerve indicated that endplates generally receive no more than two inputs, although a third, very weak input may occasionally be present (Morrison-Graham, 1983). For clarity, the EPP produced by the isolated motor unit at polyinnervated junctions will be referred to as the "identified" EPP, while the difference between the identified EPP and the EPP observed when the whole nerve is stimulated will be called the secondary EPP. The secondary EPP is thus generated by 


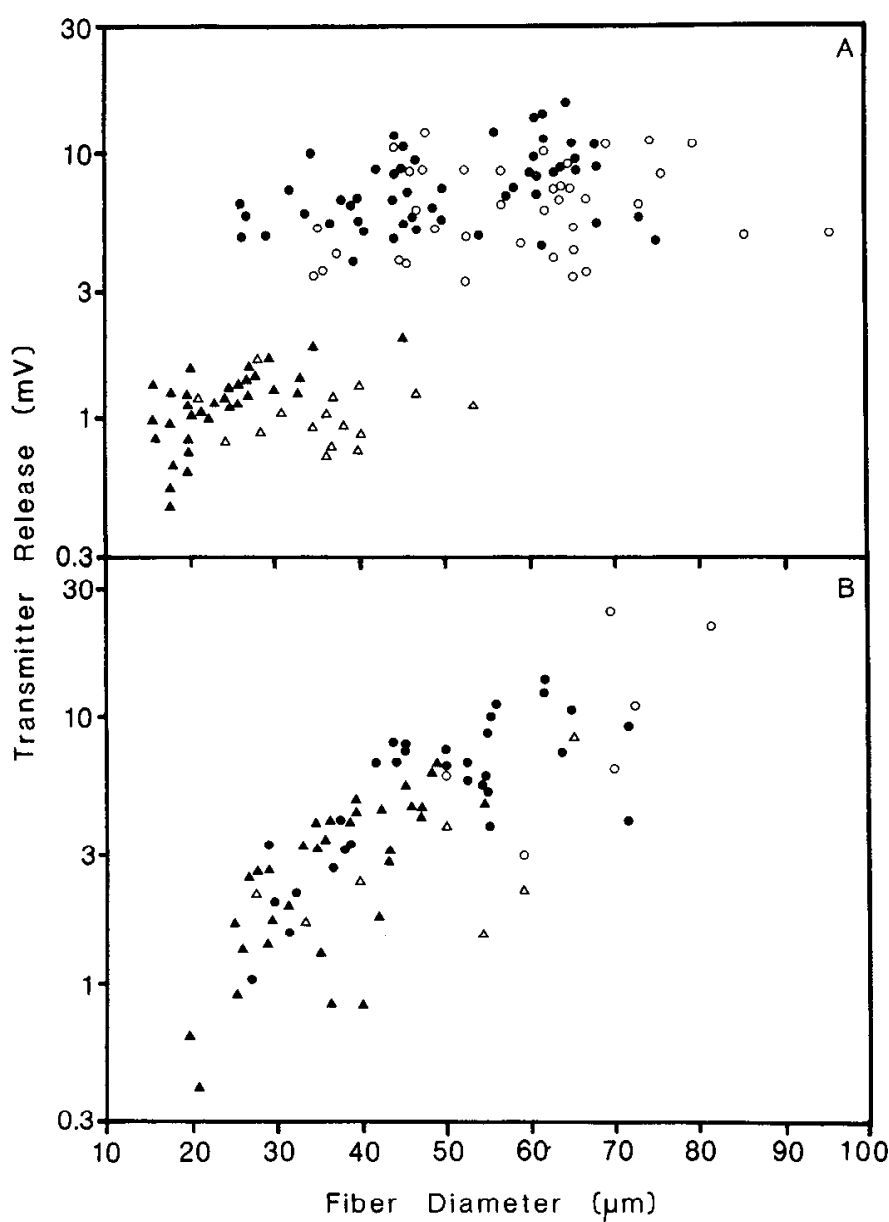

Figure 6. Transmitter release (EPP normalized for input resistance) vs. muscle fiber diameter (calculated from input resistance). $A$, data for singly innervated fibers. Triangles $(\boldsymbol{\Lambda}, \Delta)$ and circles $(\mathbf{0}, 0)$ are data from small and large twitch motor units, respectively. Filled and empty symbols are data taken from Northern and Southern $R$. pipiens, respectively. $B$, transmitter release for polyinnervated endplates, expressed as the total release (the identified plus the secondary response together). Symbols are as in $A$. Linear correlation coefficients for large and small motor unit populations in $B$ are 0.61 and 0.64 , respectively $(\mathrm{p}<0.01)$.

a motor axon other than the isolated axon. (No primacy in innervation order, EPP amplitude, or terminal size is implied by this nomenclature.)

Frequency of polyinnervation. The overall percentage of polyinnervated muscle fibers from isolated motor units was $36 \%$ (89 of 250), being somewhat higher in the small motor units than in the large motor units (47 and $31 \%$, respectively). This overall value is 2.2 times the frequency obtained by graded whole nerve stimulation of curare-blocked c.p. muscles $(16 \%$; Rotshenker and McMahan, 1976; Weakly and Yao, 1983). Moreover, the frequency of polyinnervation in Northern frogs was twice that of the larger Southern frogs, with values of $44 \%$ (69 of 157) and $22 \%$ (20 of 93), respectively. The large discrepancy between the frequency found in the present work and the previous estimates can most likely be attributed to the difficulty in reliably detecting small EPPs which add onto larger, fluctuating EPPs. The present method for detection circumvents the problem to some extent by stimulating one of the inputs to a shared endplate in complete isolation. Small motor unit EPPs in polyinnervated junctions were often barely detectable above noise and would surely have been missed if added onto an EPP of several millivolts. Furthermore, as noted above, some EPPs are normally below threshold. These may be completely unde-

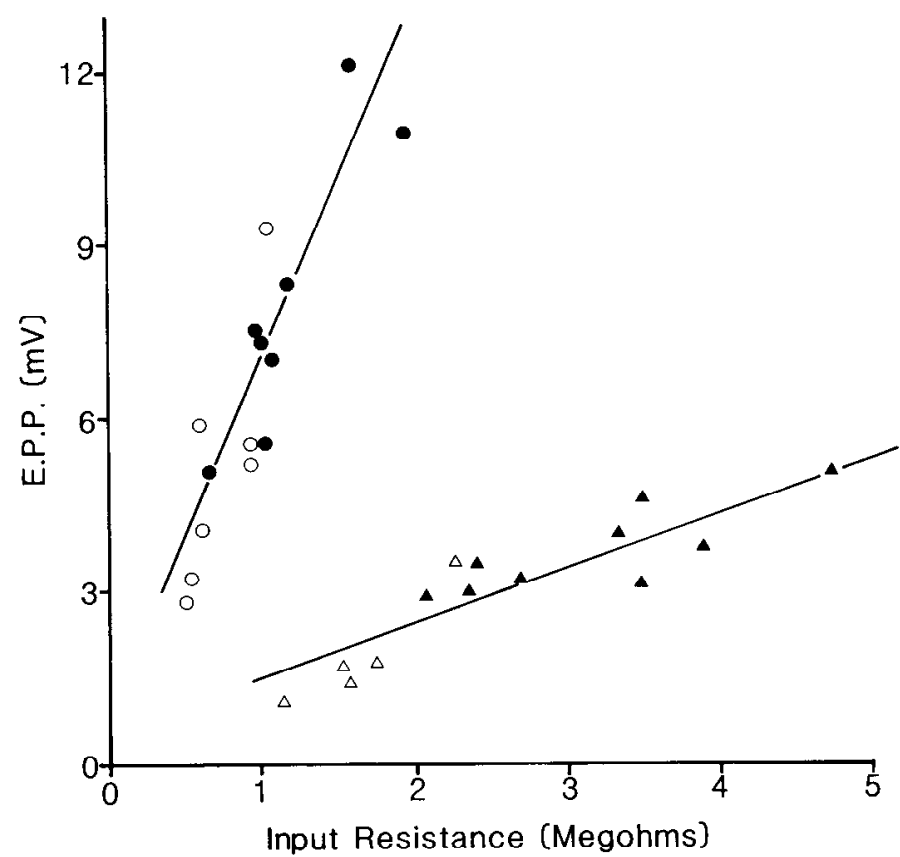

Figure 7. Motor unit mean EPP amplitude vs. mean muscle fiber input resistance. Triangles and circles are data from small and large twitch motor units, respectively. Filled and empty symbols are data taken from Northern and Southern $R$. pipiens, respectively. Correlation coefficients are 0.87 for the large motor units and 0.78 for the small motor units $(p<0.01)$.

tectable after curarization. Thus, it seems likely that the frequency of polyinnervation that exists in the frog c.p. is much higher than previously believed and may, for small motor units, exceed $50 \%$. Unexpected high values for the incidence of polyinnervation have also been noted in the frog sartorius muscle after blocking contraction with formamide (I Ierrera, 1984).

The size of EPP components. The average size of - the EPP component produced by individual motor axons at polyinnervated synapses was only $48 \%$ of the mean EPP produced at singly innervated synapses (Table I), consistent with the findings of Angaut-Petit and Mallart (1979) and Weakly and Yao (1983) in anuran muscle, and Hume and Purves (1983) in the rabbit ciliary ganglion. Similarly, within each motor unit size class, the EPPs were sharply reduced in amplitude when associated with polyinnervation (Table I). Interestingly, for these polyinnervated synapses, identificd inputs from large motor units were still consistently stronger than identified inputs from small motor units (means $\pm \mathrm{SD}: 3.0 \pm 2.1 \mathrm{mV}$ vs. $1.0 \pm$ $0.8 \mathrm{mV}$, respectively). When EPPs are normalized for input resistance (Table $\mathrm{I}$ ), the resulting estimation of transmitter release differs 6 -fold for the large and small motor units (as it does for singly innervated junctions; see above). Taken together with the results from the singly innervated synapses, it is apparent that the strength of a synapse is strongly influenced by the identity of its motor unit. Even those synapses which are subject to powerful local competitive influences still reflect their motor unit identity in their EPP amplitude and transmitter release.

Although the identity of the motor unit generating the secondary EPP could not be determined precisely (since the secondary EPP was only seen by stimulating all c.p. axons together; see "Materials and Methods"), we felt it was of interest to see if the secondary motor unit's size might be inferred from its EPP amplitude. Surprisingly, the mean secondary EPP was the same, regardless of the size of the motor unit producing the identified EPP. Moreover, the mean secondary FPP was not different from the mean identified EPP contributed by large 
twitch motor units (Table 1). While the size of the secondary component was variable and could conceivably be produced by a motor unit of any twitch size, the similarity of its mean value to the mean EPP contributed by identified large twitch motor units suggests that this secondary component was most frequently produced by a large twitch motor unit. This conclusion is strengthened by comparing histograms of identified and secondary EPP sizes for synapses polyinnervated by large and small twitch motor units (Figure 8). The distributions for secondary EPPs and identified large motor unit EPPs were not significantly different from one another, but did differ markedly from the distribution of identified small motor unit EPPs (significance determined by a $\chi^{2}$ test of homogeneity). It might seem puzzling that identified large motor unit EPPs are so rarely accompanied by a secondary EPP from a small motor unit. However, when the identified EPP is large, it is difficult to detect the addition of very small, fluctuating secondary
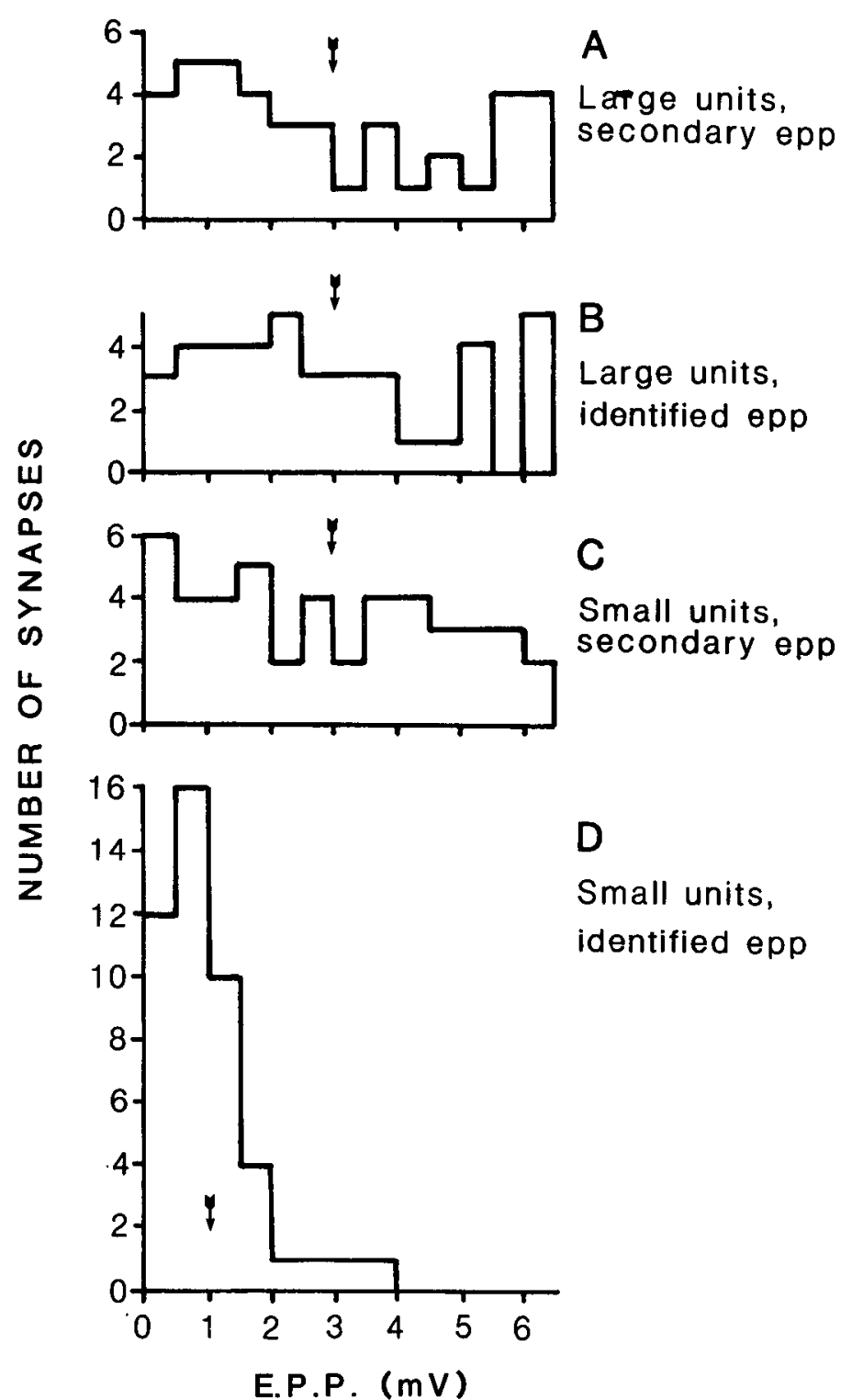

Figure 8 . Histograms of identified and secondary EPP components at polyinnervated synapses. $A$ and $B$ are secondary and identified components (respectively) of synapses whose identified EPP was contributed by a large twitch motor unit. $C$ and $D$ show secondary and identified components of synapses whose identified EPP was contributed by a small twitch motor unit. Means (arrows) for $A, B, C$, and $D$ are $2.98,2.98,2.91$, and $1.00 \mathrm{mV}$, respectively (see Table I).
EPPs, and so many such cases may have been erroneously catagorized with the singly innervated endplates. It is possible, too, that such small twitch motor units comprise only a small fraction of the muscle's fibers, and so would not often overlap with large motor units when large motor units are selected for in the sampling, but would overlap with large motor units frequently when small motor unit fibers are selected for. That the secondary EPPs in the samples represented here appear to generally derive from large motor axons has a bearing on the interpretation of data on the size of polyinnervated muscle fibers (see below).

The size of polyinnervated muscle fibers. In the last section, it was shown that, when two axons converge at one endplate, the strength of each synaptic contact is diminished. Since the activity and interaction of two different axons might also affect the properties of the muscle fiber, we measured the diameter of polyinnervated muscle fibers within identified motor units. In Figure 4, frequency histograms of fiber size compare the singly and polyinnervated fibers of large and small twitch motor units. Within the population of muscle fibers belonging to small twitch motor units, the largest fibers tend to be polyinnervated. In contrast, the polyinnervated fibers of large twitch motor units were not significantly different in size from the singly innervated fibers. Since, in our samples, the secondary EPPS were apparently most often generated by large twitch motor units, these data suggest that polyinnervation by two large twitch motor unit axons produces a fiber similar in size to fibers innervated by a single large twitch motor unit axon. When axons of large and small twitch motor units both drive the same fiber, that fiber appears to be intermediate between the sizes expected for either motor unit alone. Thus, the size of a polyinnervated muscle fiber is related to the identity of hoth motor axons contacting it.

The terminal length, fiber size, and transmitter release relationship for polyinnervated synapses. Evidence obtained in these experiments supports the hypothesis that, in terms of the matching of synapse size to fiber size, polyinnervated and singly innervated synapses behave similarly. Although it was often not possible for us to clearly discern which presynaptic component of a polyinnervated synapse came from a given axonal input, the total length of the synapse was measurable. In Figure 5 , the total lengths of 13 synapses physiologically identified as being polyinnervated (slashed symbols) are compared to the diameter of their fibers. Polyinnervated junctions do not appear to be different in total length than singly innervated junctions in any given fiber size class. This suggests that the length of the individual axon components of the polyinnervated endplates are shorter than the lengths of singly innervated junctions on fibers of the same size, in keeping with the observation that such components are also physiologically weaker.

As shown above, the transmitter release of singly innervated synapses within a twitch size group was relatively uniform, despite differences in fiber size (Fig. 6A). Since polyinnervated fibers combine two different motor axons at one endplate, it was of interest to see how this combined transmitter output changed over their range of fiber size. In Figure 6B, the summed release of the identified and secondary components at each endplate is plotted as a function of fiber diameter. In contrast to the behavior of singly innervated endplates, the total release at shared endplates closely parallels the size of the muscle fiber. As might be expected, however, far greater variability is observed in the release from individual identified and secondary terminals than in their combined output. Figure 9 shows the relationship between release and diameter for large and small motor unit identified inputs $(\square)$ as well as the corresponding release from the secondary inputs $(\square)$. Lines connecting an identified and a secondary input identify the pair as innervating the same fiber. This figure reveals several interesting points 


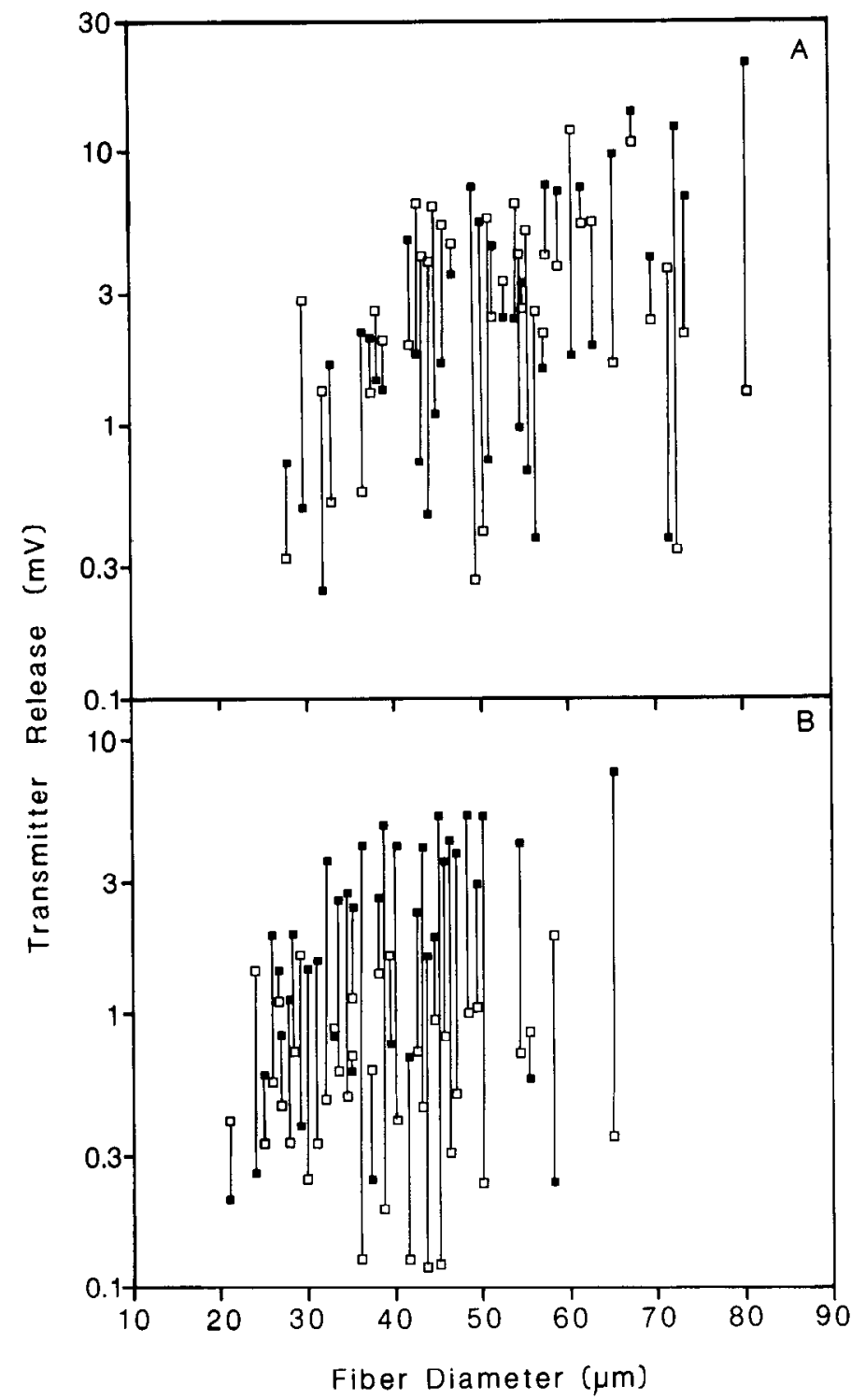

Figure 9. Transmitter release (EPP normalized for input resistance) vs. muscle fiber diameter for the individual components of polyinnervated endplates. $\square$, identified inputs; $\mathbf{\square}$, associated secondary inputs. Lines connecting identified and secondary inputs indicate that they originate from the same endplate. Identified inputs from large and small motor units are shown in $A$ and $B$, respectively.

about the strength of polyinnervated synapses. (1) The individual inputs to each endplate vary widely in strength, and even large, synaptically strong motor units may form some very weak synapses (in agreement with inferences made from motor unit tension measurements in the frog sartorius; Grinnell and Trussell, 1983). (2) The correspondence between release and diameter is poor for individual components of each endplate, especially for small motor unit inputs. (3) While the strength of the identified and secondary inputs at one endplate may be similar or very different, their combined transmitter output appears to be appropriate for the size of the fiber they are found on (see Fig. $6 B$ ). It will be suggested below that this correspondence is the result both of the effects of muscle fiber size on synapse size and the sharing of a finite postsynaptic area by physiologically different terminals (see "Discussion").

From these data, we conclude that the strength of polyinnervated junctions is a function both of motor unit identity, which may determine a general range of transmitter release, and the nerve terminal size, which varies with fiber size and seems to vary proportionately in transmitter release. The singly innervated synapses also show a parallel between terminal length and muscle fiber size, but, unlike the polyinnervated synapses, their transmitter release to a single stimulus appears less dependent on muscle fiber size.

\section{Variability within single motor units}

The results presented above indicate that muscle fibers and synapses in the c.p. may differ according to their motor unit identity. As in any population, the muscle fiber and synaptic members of a single motor unit would be expected to exhibit some variation. However, this variation may serve to indicate more precisely the degree of influence a motoneuron has in regulating motor unit properties. In Figure 10, the range in muscle fiber diameter and transmitter release is presented for 15 individual motor units in which three or more cells were found. Thick lines show the range of properties of singly innervated endplates; thinner lines are used where the motor unit's polyinnervated endplates extend this range. These experiments are arranged in order of decreasing motor unit twitch size. As this figure shows, we have observed up to 2.5-fold differences in muscle fiber diameter and 4-fold differences in transmitter release among apparently singly innervated fibers in a single motor unit, all of which presumably had experienced the same activity pattern. Possibly, such wide ranges of values are generated by the extreme members of a normally distributed population; the small sample sizes for each motor unit prevent us from clarifying this. In any case, these data do suggest that, in addition to motor unit activity, other factors may play important roles in determining the properties of a motor unit's fibers and synapses (see "Discussion"). For reasons discussed above (see the discussion on size of EPP components and polyinnervated muscle fibers), inclusion of polyinnervated synapses can markedly extend the range in these properties. Thus, even motor units of very different twitch size may overlap to some extent in their range of muscle fiber diameter and transmitter release.

\section{Motor unit size in the c.p.}

The tension evoked by a motor unit reflects both the number and the cross-sectional area of fibers in the motor unit. Since glycogen depletion techniques have not proven useful for anuran muscle (M. S. Letinsky, personal communication), it is difficult to determine the number of fibers contacted by a single motor axon. For the sartorius, the extremely wide range of motor unit tetanic tension (over 60 -fold) was larger than could be accounted for on the basis of fiber size alone (Grinnell and Trussell, 1983). The differences observed in mean safety factor seem to parallel differences in the apparent number of fibers in sartorius motor units. However, the range of motor unit tetanic tensions in the c.p. (13-fold) is narrower than in the sartorius. The 2.2-fold difference in average input resistance observed between the small and large class of motor units should correspond to about a 2.7-fold difference in fiber crosssectional area and, presumably, motor unit tension. While the average twitch tensions of the large units was 4.6 times that of the small units, some of this is explainable by the presence of subthreshold synapses in small motor units. Therefore, the small and large motor units should differ less in tetanic tension than in twitch tension, as indicated also by their more similar mean fiber cross-sectional area. From consideration of these arguments, one might suppose that the number of fibers among c.p. motor units is relatively uniform, with differences in motor unit tension deriving largely from fiber size differences. On the other hand, these estimations of innervation ratio are indirect; it is our feeling that, given the disparity in other properties among motor units, c.p. motor units are likely to differ in fiber number, probably in the same direction as twitch strength. 

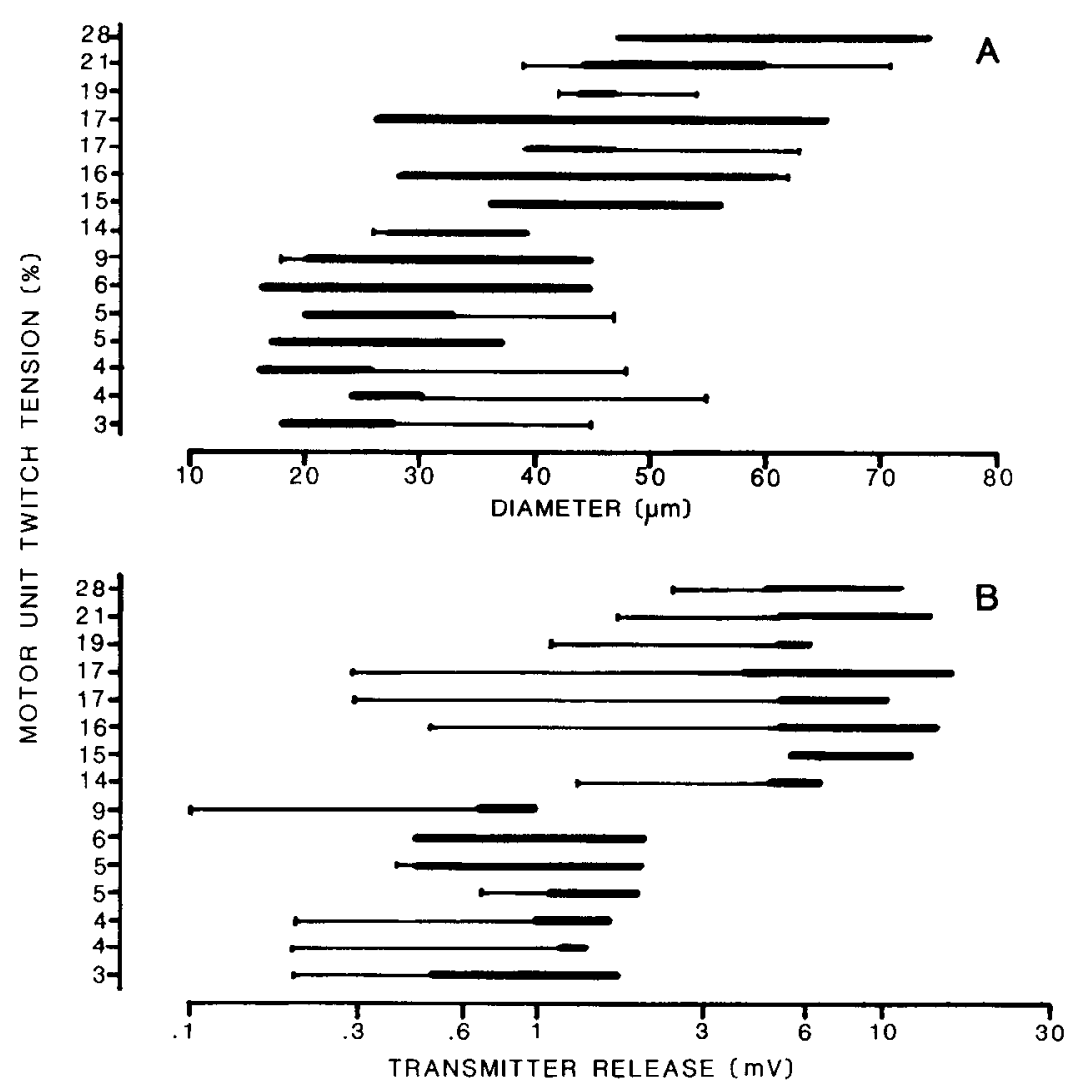

Figure 10. The range of muscle fiber diameter $(A)$ and transmitter release ( $B$; EPP normalized for input resistance) within 15 individual motor units from Northern $R$. pipiens c.p. muscles. Motor units were included only if three or more singly innervated fibers were found and are arranged in order of decreasing relative twitch tension (percentage of whole muscle twitch). Thick lines show the range of diameter and release for singly innervated fibers, while thin lines indicate where polyinnervated fibers fell outside the range of singly innervated fibers.
While the motor unit size is generally defined in terms of the number of fibers the motoneuron contacts, it is useful also to consider the size of a motoneuron's field of innervation in terms of the total synaptic area the motoneuron supports. As noted above, the expected mean terminal length for small motor unit singly innervated junctions should be less than half the mean length of large unit synapses. Therefore, even assuming that motor units in the c.p. have identical innervation ratios, the total synaptic area of all singly innervated junctions maintained by the average small twitch motor unit must be less than half that of the average large twitch motor unit. Addition of the terminal area contributed by individual axons at polyinnervated junctions to these estimates would only serve to increase the disparity between the different motor units: the terminal component an individual axon contributes to a polyinnervated endplate is likely to be shorter than the total endplate size, and a higher incidence of polyinnervation is seen in small motor units than in large motor units. Thus, it appears that motor units evoking small twitch tensions differ from more powerful motor units not only by innervating smaller muscle fibers and by having a reduced synaptic efficacy, but also by supporting a smaller total synaptic area.

\section{Muscle fiber contraction kinetics}

The differences observed in muscle fiber size with motor unit twitch size raise the possibility that fiber contractile properties might also be a function of motor unit identity in the c.p. In the frog sarlorius, the fall in tetanus-twitch ratio with motor unit size is paralleled by a shortening of the twitch rise-time (Grinnell and Trussell, 1983). When twitch rise-times were measured for 85 c.p. motor units, no significant differences were observed between the mean rise-time (base line-to-peak) of motor units evoking less than $4 \%$ and greater than $15 \%$ of the whole muscle tetanus tension, groupings which had revealed significant rise-time differences in the sartorius. However, some of the similarity in rise-time among small and large motor units appears to result from base line differences between animals: when a muscle's motor unit rise-times are normalized to the fastest rise-time in the experiment, and then data from different muscles are pooled, a clear-cut trend for small motor unit twitches to be slower become apparent (Fig. 11).

\section{Discussion}

The efficacy of neuromuscular transmission is determined by both pre- and postsynaptic elements: the size of the nerve terminal, the amount of transmitter relcased per unit length of terminal, the sensitivity of receptors to the transmitter, and

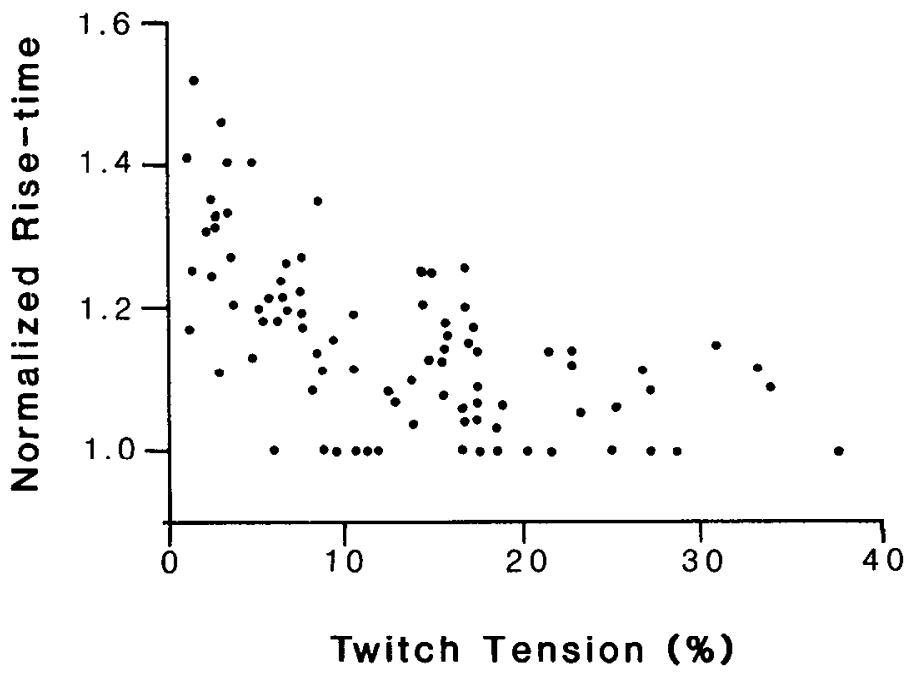

Figure 11. Normalized rise-times (base line-to-peak) of c.p. motor unit twitch plotted against relative twitch size of the motor units. Risetimes were normalized to the fastest rise-time in each experiment to aid in revealing trends among the motor units in each muscle. Shown are 85 motor units taken from 13 muscles. 
the postsynaptic input resistance. In practice, since the quantal current is relatively uniform among the different fibers in a muscle, the efficacy of transmission seems to reflect the number of quanta released and the size of the muscle fiber. To a major extent, differences in release are the result of "intrinsic" differences between motoneurons. In the c.p. muscle of the frog, the size of the synapse and of the target muscle fiber, as well as the level of transmitter release of the nerve terminal, appears in large part to be a function of the motoneuron forming the synapse. Even at polyinnervated junctions, the strength of individual components suggests that release is characteristic of other terminals in the unit, but reduced to the extent that they only occupy part of the junction.

Transmitter release appears to be relatively uniform among the singly innervated muscle fibers of any given motor unit, especially when comparing the fibers of motor units that differ markedly in twitch size. Although transmitter release and motor unit twitch size are not well correlated within the motor unit size groupings we have employed, it seems probable that this is the result of the small sample of fibers studied within each motor unit, rather than the absence of such a correlation. Since in any given muscle there is a continuous gradation in motor unit twitch strengths (Fig. 2), it is likely that axons of progressively larger twitch motor units innervate larger muscle fibers and release more transmitter. Our data do not give evidence for physiologically distinct populations of motoneurons innervating twitch fibers in the c.p., although this may occur in other anuran muscles (Lännergren and Smith, 1966; B. Nudell, unpublished observations).

Origin of motor unit synaptic properties. The differences in transmitter release, fiber size, safety factor, contraction kinetics, and total synaptic area observed between small and large twitch units probably reflect processes that only a thorough developmental study would clarify. One can imagine many different mechanisms for the origin of such diversity in the adult. It is possible, for example, that the capacity of motoneurons to form and maintain synapses, release transmitter, and induce growth in their muscle fibers is genetically preset at different levels, so that each muscle receives a physiologically diverse population of motoneurons from the outset. On the other hand, such differences might arise developmentally, as the result of competitive peripheral interactions with more precocious or intrinsically robust neurons suppressing weaker ones, as a response to different patterns of electrical activity, or through the increasing requirements placed on neurons of different capacity. In the latter case, it may be that the properties of fibers and synapses early in the animal's life are relatively uniform, and as fibers grow and nerve terminal area enlarges, only a subpopulation of the motoneuron pool is capable of effectively keeping up with the added demand.

It is surprising that, among singly innervated muscle fibers, synapses on larger fibers do not release more transmitter than synapses on smaller fibers when the synapses belong to the same motor unit size class (Fig. 6A), even when taken from animals that differ markedly in size. This result may be interpreted to mean that the transmitter release of singly innervated synapses does not adjust for differences in muscle fiber input resistance. Possibly, changes in quantal release with input resistance that occur when the animals are younger and synapses smaller (Morrison-Graham, 1983) may not operate at later stages of development. Thus, a motoneuron's level of transmitter release may reach a plateau with maturity. However, the maximum level of release a motoneuron sets for its terminals does not necessarily represent a peak in the neuron's capability: experimental reduction of a motoneuron's innervation field or axotomy of the contralateral homologous motoneurons are observed to increase dramatically the transmitter output of its terminals without corresponding changes in terminal length (Herrera and Grinnell, 1980, 1981).

If a plateau is reached for the transmitter release of a neuron's singly innervated synapses, then one might expect it to be in spite of continued growth of its synapses, since muscle fiber size and terminal length are closely related within any one muscle. If terminal growth may occur without a corresponding increase in release, then one must ask what are the factors that induce terminal growth and what is its functional significance? There may be some still unknown trophic benefit to either the muscle fiber or the nerve terminal dependent on this match in size, even when it is not accompanied by corresponding increases in evoked transmitter output. On the other hand, it is possible that the transmitter release evoked by single stimuli may not be an adequate measure of what terminal growth is directed towards: if firing frequencies are normally high (Sayers and Tonge, 1983), terminals of lower release per unit length would be expected to show greater facilitation and less depression than terminals of higher release per unit length (Nudell and Grinnell, 1982). Thus, the larger terminals in a given motor unit may in fact be capable of much greater release under normal firing conditions, as required for the larger muscle fibers they innervate. Measurements of the length and strength of nerve terminals within motor units throughout development should clarify the extent to which transmitter release increases in parallel with synaptic size and may suggest other factors to which the motoneuron and its terminals are capable of responding.

Strength of identified motor unit components at polyinnervated junctions. When an identified axon contributes a synapse to a polyinnervated junction, its output is smaller than at singly innervated junctions (Table I). This is consistent with the observation that the total terminal length of polyinnervated junctions does not differ in any obvious way from the terminal length on singly innervated fibers of the same size. We conclude that when two axons share the same postsynaptic space, the synaptic strength of cach is reduced in proportion to the reduced amount of terminal. This, however, implies a close relationship between terminal size and release, while the evidence discussed above suggests that a motoneuron's average transmitter release at singly innervated junctions is set at a constant level over a wide range of fiber (and presumably terminal) sizes. The explanation for this difference is unclear, but may lie in the reduced size of each component input to a polyinnervated junction, compared with single inputs to fibers of the same size. As suggested above, there may be a period during which the amount of transmitter released from a nerve terminal increases with terminal length, but upon reaching a critical output level further terminal growth would not be paralleled by increased transmitter output. The relatively short terminal components present at polyinnervated junctions might still be increasing their output with increases in length.

Variability within motor units. Individual synapses exhibit a strength determined principally by the identity of the motoneuron and the presence of polyinnervation. Nevertheless, we have observed 2- to 3 -fold variation in transmitter release and fiber diameter among singly innervated synapses of single motor units. Several explanations for this variability are plausible, among them: (1) intrinsic differences in the ability of muscle fibers to respond with growth to equivalent nerve activity or release, (2) the effect of undetected polyinnervation (see below), (3) different levels of maturity among the fibers of a motor unit, and (4) differences in axon diameter among the branches of a single axon, which might affect the relative distribution of supportive materials throughout the motor unit. With regard to the fourth possibility, no consistent tendency was observed for the more medially located synapses to be weakest. However, the effects of axon diameter may nonethe- 
less be apparent at a finer level of axon branching, for example in the immediately preterminal portions of the axon.

This study has presented evidence that polyinnervation in the c.p. is more common than previously believed. Indeed, our measurements may still be underestimations of the true frequency. This has important implications for the interpretation of our results. One possible reason for the large scatter in the size of large twitch motor unit EPPs within an experiment may lie in the presence of undetected polyinnervation. If a small twitch motor unit's EPP at a polyinnervated junction was below detectability, but its terminal component occupies enough of the available endplate area to prevent the full growth of a stronger input, the latter might be noticeably reduced in strength compared to singly innervated inputs. Indeed, the synapses a motoneuron makes may show an intrinsic variety of strengths and abilities to suppress or eliminate secondary inputs early in life. From this, one would expect that even strong motor units would have some weaker synapses which would be at polyinnervated endplates.

The determination of muscle fiber properties. The matching of presynaptic and postsynaptic properties we have observed is not surprising in light of the evidence for neural regulation of muscle fiber characteristics (Buller et al., 1960; Close, 1969; Guth et al., 1970; L $\phi \mathrm{mo}$, et al., 1974; Salmons and Sreter, 1976; Buller and Pope, 1977; Nemeth et al., 1981). Even among polyinnervated muscle fibers, the size of the postsynaptic fiber seems to reflect the influence of both motor axons contacting it. Thus, muscle fibers innervated by the axons of two different large twitch motor units are similar in size to fibers innervated by only one large twitch motor unit. In contrast, when fibers are innervated by a large and a small twitch motor unit axon, the fiber size is intermediate between that of singly innervated large and small motor unit fibers (Table 1). It would seem likely that the trophic and/or activity contributions of nerve to muscle are responsible for these effects. This conclusion was also reached by Ridge and Thomson (1980a), who observed that fibers in a Xenopus toe muscle may be polyinnervated by motor units of dissimilar twitch size, and that motor units contain muscle fibers of varying size and contractile properties. However, our data may also be consistent with the hypothesis that the nerve's influence is only permissive, rather than regulatory, and that during development certain motor axons specifically innervate fibers of a given, predetermined type (Gordon, 1983; Thompson et al., 1983). In this case, fibers which will be of intermediate size in the adult might tend to attract (or fail to eliminate) both large and small motor unit axons. Clearly, the properties of the motoneuron, and the activity pattern it evokes, cannot be the sole determinant of fiber size, as evidenced by the variability among singly innervated fibers within single motor units. Since these hypotheses may not be mutually exclusive, it will be of interest to establish the specificity of synapse formation within any given frog twitch muscle, and to see what normally determines the size and contractile properties of muscle fibers.

\section{References}

Angaut-Petit, D., and A. Mallart (1979) Dual innervation of endplate sites and its consequences for neuromuscular transmission in muscles of adult Xenopus laevis. J. Physiol. 289: 203-218.

Anzenbacher, H., and W. Zenker (1963) Über die Grossenbeziehung der Muskelfasern zu ihren motorischen Endplatten und Nerven. Z. Zellforsch. Mikrosk. Anat. 60: 860-871.

Bennett, M. R., and A. G. Pettigrew (1975) The formation of synapses in amphibian striated muscle during development. J. Physiol. 252: 203-239.

Buller, A. J., and R. Pope (1977) Plasticity in mammalian skeletal muscle. Phil. Trans. R. Soc. Lond. B 278: 295-305.

Buller, A. J., J. C. Eccles, and R. M. Eccles (1960) Interaction between motoneurons and muscles in respect of their characteristic speeds of their responses. J. Physiol. 150: 417-439.

Burke, R. E. (1981) Motor units: anatomy, physiology, and functional organization. In Handbook of Physiology. The Nervous System. J. M. Brookhart, V. B. Mountcastle, V. B. Brooks, and S. R. Geiger, eds., Sect. 1, Vol. II, Part 1, pp. 345-422, American Physiological Society, Bethesda, MD.

Burke, R. E., and P. Tsairis (1973) Anatomy and innervation ratios in motor units of cat gastrocnemius. J. Physiol. 234: 749-765.

Close, R. (1969) Dynamic properties of fast and slow skeletal muscles of the rat after nerve cross-union. J. Physiol. 274: 331-346.

Coërs, C.(1955) Les variations structurelles normales et pathologiques de la jonction neuromusculaire. Acta Neurol. Psychiat. Belg. 55: 741 866.

Coërs, C., and A. L. Woolf (1959) The Innervation of Muscle. A Biopsy Study, Oxford, Blackwell Scientific Publishing Co.

Davis, W. J. (1971) Functional significance of motoneuron size and soma position in swimmeret system of the lobster. J. Neurophysiol. 34: $274-288$.

Dennis, M. J., L. Ziskind-Conhaim, and A. J. Harris (1981) Development of neuromuscular junctions in rat embryos. Dev. Biol. 81: 266279 .

Gordon, H. (1983) Postnatal development of motor units in rat and rabbit soleus muscles. Ph.D. thesis, California Institute of Technology.

Granbacher, N. (1971) Über die Grossenbezelhungen der Muskelfasern zu ihren motorischen Endplatten und nerven bei IIypertrophie und Atrophie. Z. Anat. Entwicklungsgesch. 135: 76-87.

Grinnell, A. D., and A. A. Herrera (1980) Physiological regulation of synaptic effectiveness at frog neuromuscular junctions. J. Physiol. 307: 301-317.

Grinnell, A. D., and A. A. Herrera (1981) Specificity and plasticity of neuromuscular connections: long-term regulation of motoneuron function. Prog. Neurobiol. 17: 203-282.

Grinnell, A. D., and L. O. Trussell (1983) Synaptic strength as a function of motor unit size in the normal frog sartorius. J. Physiol. 338: 221-241.

Grinnell, A. D., M. S. Letinsky, and M. B. Rheuben (1979) Competitive interaction between foreign nerves innervating frog skeletal muscle. J. Physiol. 289: 241-262.

Guth, L., F. J. Samaha, and R. W. Albers (1970) The neural regulation of some phenotypic differences between the fibers of mammalian skeletal muscle. Exp. Neurol. 26: 126-135.

Harris, C. (1954) The morphology of the myoneural junction as influenced by neurotoxic drugs. Am. J. Pathol. 30: 501-519.

Harris, J. B., and R. R. Ribchester (1979) The relation between endplate size and transmitter release in normal and dystrophic muscles of the mouse. J. Physiol. 296: 245-265.

Herrera, A. A. (1984) Polyneuronal innervation and quantal transmitter release in formamide-treated frog sartorius muscles. J. Physiol. (Lond.) 355: 267-280.

Ilerrera, A. A., and A. D. Grinnell (1980) Transmitter release from motor nerve terminals depends on motor unit size. Nature 287: 649651.

Herrera, A. A., and A. D. Grinnell (1981) Contralateral denervation causes enhanced transmitter release from frog motor nerve terminals. Nature 291: 495-497.

Hume, R. I., and D. Purves (1983) Apportionment of the terminals from single preganglionic axons to target neurons in the rabbit ciliary ganglion. J. Physiol. 338: 259-275.

Katz, B. (1948) The electrical properties of the muscle fibre membrane. Proc. R. Soc. Lond. B 135: 506-534.

Katz, B., and S. Thesleff (1957) On the factors which determine the amplitude of the "miniature end-plate potential. J. Physiol. 137: 267278.

Kelly, S. S., and N. Robbins (1983) Progression of age changes in synaptic transmission at mouse neuromuscular junctions. J. Physiol. 343: 375-383.

Korneliussen, H., and O. Waerhaug (1973) Three morphological types of motor nerve terminal in the rat diaphragm and their possible innervation of different muscle fiber types. Z. Anat. Entwicklungsgesch. 140: 73-84.

Krnjevic, K., and R. Miledi (1958) Motor units in the rat diaphragm. J. Physiol. 140: 427-439.

Kugelberg, E., L. Edström, and M. Abbruzzese (1970) Mapping of 
motor units in experimentally innervated rat muscle. J. Neurol. Neurosurg. Psychiatry 33: 319-329.

Kuno, M., S. A. Turkanis, and J. N. Weakly (1971) Correlation between nerve terminal size and transmitter release at the neuromuscular junction of the frog. J. Physiol. 213: 545-556.

Lännergren, J., and R. S. Smith (1966) Types of muscle fibres in toad skeletal muscle. Acta Physiol. Scand. 68: 263-274.

Letinsky, M. S. (1974) The development of nerve-muscle junctions in Rana catesbeiana tadpoles. Dev. Biol. 40: 129-153.

Letinsky, M. S., and P. A. DeCino (1980) Histological staining of preand postsynaptic components of amphibian neuromuscular junctions. J. Neurocytol. 9: 305-320.

Letinsky, M. S., K. Fischbeck, and U. J. McMahan (1976) Precision of reinnervation of original postsynaptic sites in muscle after nerve crush. J. Neurocytol. 5: 691-718.

Linden, D. C., and M. S. Letinsky (1983) Correlated nerve and muscle differentiation in the bullfrog cutaneous pectoris. In The Physiology of E'xcitable Cells, A. D. Grinnell and W. J. Moody, eds., pp. 423-433, Alan R. Liss, Inc., New York.

Lnenicke, G. A., and DeF. Mellon (1983) Transmitter release during normal and altered growth of identified muscle fibers in the crayfish. J. Physiol. 345: 285-296.

L. $\phi \mathrm{mo}$, T., R. H. Westgaard, and H. A. Dahl (1974) Contractile properties of muscles: control by pattern of muscle activity in the rat. Proc. R. Soc. Lond. B 187: 99-103.

Luff, A. R., and U. Proske (1976) Properties of motor units of the frog sartorius muscle. J. Physiol. 258: 673-685.

Magleby, K. L., B. S. Pallotta, and D. A. Terrar (1981) The effect of (+)-tubocurarine on neuromuscular transmission during repetitive stimulation in the rat, mouse, and frog. J. Physiol. 312: 97-113.

McLachlan, E. M., and A. R. Martin (1981) Non-linear summation of end-plate potentials in the frog and mouse. J. Physiol. 311: 307-324.

Morrison-Graham, K. (1983) An anatomical and electrophysiological study of synapse elimination at the developing frog neuromuscular junction. Dev. Biol. 99: 298-311.

Nemeth, P., D. Pette, and G. Vrbová (1981) Comparison of enzyme activities among single muscle fibers within defined motor units. J. Physiol. 311: 489-495.

Nudell, B. M., and A. D. Grinnell (1982) Inverse relationship between transmitter release and terminal length in synapses on frog muscle fibers of uniform input resistance. J. Neurosci. 2: 216-224.

Nudell, B. M., and A. D. Grinnell (1983) Regulation of synaptic position, size, and strength in anuran skeletal muscle. J. Neurosci 3: $161-176$.

Otsuka, M., M. Endo. and Y. Nonomura (1962) Presynaptic nature of neuromuscular depression. Jpn. J. Physiol. 12: 573-584.

Ridge, R. M. A. P., and A. M. Thomson (1980a) Polyneuronal innervation: mechanical properties of overlapping motor units in a small foot muscle of Xenopus laevis. I. Physiol. 306: 29-39.

Ridge, R. M. A. P., and A. M. Thomson (1980b) Electrical responses of muscle fibres in a small foot muscle of Xenopus laevis. J. Physiol. 306: $41-49$.

Rotshenker, S. (1982) Transneuronal and peripheral mechanisms for the induction of motor neuron sprouting. J. Neurosci. 2: 1359-1368.

Rotshenker, S., and U. J. McMahan (1976) Altered patterns of innervation in frog muscle after denervation. J. Neurocytol. 5: 719-730.

Salmons, S., and F. Sreter (1976) Significance of impulse activity in the transformation of skeletal muscle type. Nature 263: $30 \cdot 34$.

Sayers, H., and D. A. Tonge (1983) Persistence of extra-junctional sensitivity to acetylcholine after reinnervation by a foreign nerve in frog skeletal muscle. J. Physiol. 335: 569-575.

Thompson, W. J., L. Sutton, and D. A. Riley (1983) Histochemistry of single motor units during synapse elimination in rat soleus muscle. Soc. Neurosci. Abstr. 9: 321.

Trussell, L. O. (1983) Synaptic properties of motor units in the frog cutaneous pectoris muscle. Soc. Neurosci. Abstr. 9: 858.

Weakly, J. N., and Y.-M. Yao (1983) Synaptic efficacy at singly- and dually-innervated neuromuscular junctions in the frog, Rana pipiens. Brain Res. 273: 319-323. 